\title{
Juegos de azar y casinos: la experiencia española y una sugerencia de debate doctrinal para Brasil
}

\author{
José Eugenio Soriano García ${ }^{1}$ \\ Cláudia Ribeiro Pereira Nunes ${ }^{2}$
}

\section{Resumen}

La tradicional aproximación doctrinal a los juegos de azar, solía hacerse desde dos Códigos, el Civil, para limitarlo, y el Código Penal para prohibirlo. Pero la moderna regulación de juegos de azar se ordena desde el Derecho Público y más concretamente desde el Derecho Administrativo, en cuanto se trata de una intervención pública sobre un tipo de esparcimiento de carácter recreativo, vinculado al ocio y al turismo. Ese es el objetivo general del artículo, que resulta del esfuerzo conjunto entre académicos de Brasil (UVA) y España (UCM) sobre este tema concreto, juegos de azar y casinos. En particular, se analiza la experiencia española, con la brevedad que requiere el caso, al objeto de ofrecer una experiencia comparada que pueda resultar útil para ayudar el debate doctrinal.

Palabras-llaves: Posible función social. Regulación. Riesgo aleatorio. Abstract

\footnotetext{
${ }^{1} \mathrm{PhD}$. Catedrático de Derecho Administrativo. Universidad Complutense de Madrid (UCM). E-mail: jesorian@der.ucm.es .

${ }^{2}$ PhD. Professora Colaboradora do Mestrado. Universidade Federal do Amazonas (UFAM). Visiting Fellow at Yale University. E-mail: claudia.ribeiro@yale.edu .
} 
The traditional approach to the Spanish gambling regulation has fallen traditionally whitin the scope of the two Codes: the Civil Code, which set up their limits, and the Penal Code, which defines the prohibited practices. But the modern approach to gambling and games of chance regulation is done from the Public Law, and in particular, the Administrative Law on the grounds of the public intervention on recreational practices linked with leisure and tourism. The general objective of this paper, which results from the joint analysis of scholars from Brazil (UVA) and Spain (UCM), is focused in gambling and casinos. Particularly, it analyses in short the Spanish experience, in order to allow a comparative study that can be useful to foster further doctrinal debates.

Keywords: Games of chance, Social function. Gambling Regulation. Random risk.

\section{Consideraciones Preliminares}

La existencia de juegos de azar es tan antigua como la civilización misma. Reconocidos desde la Grecia clásica, sus fundaciones se remontan a la propia mitología, con Mercurio y Selene, y a la filosofía, con Platón y sus comentarios sobre los egipcios en Las Leyes - 709b. En Roma, la Diosa Fortuna de los romanos, con su rueda y cornucopia, representa el azar.

Pasando los siglos, el viejo puritanismo expresa su frontal oposición, tal como expresa en la carta que George Washington dirigió a su sobrino en 1783, hacía del juego "la madre de todos los vicios".

Podríamos dedicar, literalmente, cientos de páginas a la historia del juego, inclusive con expresión cinematográfica (¿Quién no recuerda "El Golpe" - "The Sting?, "Casino" o mismo "El Rey del Juego", entre otras muchas de películas?), en fin constatase su decisivo impacto en la sociedad mundial. 
Hay que distinguir entre juegos privados y los organizados por el propio Estado, los primeros prohibidos en gran medida, se desarrollan en ámbitos no propiamente lucrativos sino meramente lúdicos, mientras los públicos, por el contrario, se fomentan por su impacto en el erario público a través de tasas y exacciones.

En este artículo, los juegos de azar dejan de ser tratados en este ámbito personalista y son abordados desde la perspectiva regulatoria pública, con un claro componente social, donde la participación de los demás es, resueltamente fomentada con la posibilidad de intervenir en el dinero ganado en dicho riesgo aleatorio en beneficio de la cosa pública.

La metodología empleada en este artículo, es la revisión de literatura integrada de autores españoles, y la jurisprudencia relevante, con el fin de introducir el debate en Brasil desde la vis atractiva del Derecho Público.

\section{La tradición de juegos de azar y su numerosos cambios hasta el dia de hoy}

El primer ordenamiento español, de Alfonso X - el Sabio condenaba sólo a los tahúres.

Tiempo después, ya en siglo XIX, el Código Civil Español de 1889, y referido a los juegos privados, venía incluyendo los juegos dentro de los contratos aleatorios ${ }^{3} \mathrm{y}$, específicamente, respecto de los juegos y apuestas, indicando en su Capítulo III - Del juego y de la apuesta, in verbis:

${ }^{3}$ Código Civil Español de 1889. DISPOSICIÓN GENERAL. Artículo 1790. Por el contrato aleatorio, una de las partes, o ambas recíprocamente, se obligan a dar o hacer alguna cosa en equivalencia de lo que la otra parte ha de dar o hacer para el caso de un acontecimiento incierto, o que ha de ocurrir en tiempo indeterminado. 
Artículo 1798 CP: La ley no concede acción para reclamar lo que se gana en un juego de suerte, envite o azar; pero el que pierde no puede repetir lo que haya pagado voluntariamente, a no ser que hubiese mediado dolo, o que fuera menor, o estuviera inhabilitado para administrar sus bienes.

Artículo 1799. Lo dispuesto en el artículo anterior respecto del juego es aplicable a las apuestas. Se consideran prohibidas las apuestas que tienen analogía con los juegos prohibidos.

Artículo 1800. No se consideran prohibidos los juegos que contribuyen al ejercicio del cuerpo, como son los que tienen por objeto adiestrarse en el manejo de las armas, las carreras a pie o a caballo, las de carros, el juego de pelota y otros de análoga naturaleza.

Artículo 1801. El que pierde en un juego o apuesta de los no prohibidos queda obligado civilmente. La Autoridad judicial puede, sin embargo, no estimar la demanda cuando la cantidad que se cruzó en el juego o en la apuesta sea excesiva, o reducir la obligación en lo que excediere de los usos de un buen padre de familia.

Es decir, en el Derecho Civil, los juegos y apuestas, como regla general, están prohibidos, pero es una prohibición meramente civil. Esto es, podía practicarse, pero daba lugar a una mera obligación natural, una especie de derecho suave o soft law, que permitía que se hiciera el juego pero que no suponía obligación de pago; eran en su caso, derechos no ejercitables. También, había una excepción, (ejercicio del cuerpo), lo que hoy llamaríamos "deporte", porque dependían al final de la destreza propia y no del azar. Ratificando el pensamiento, las "Circulares de la Fiscalía del Tribunal Supremo" como la de 14 de octubre de 1889, venía a confirmar que era el azar lo que se prohibía ${ }^{4}$.

Comienza el cambio con la despenalización del juego en el Real Decreto Ley 16, de 25 de febrero de 1977 se regulan los Aspectos Penales,

4 LAFAILLE, Jean-Marc. SIMONIS, Guy. El juego diseccionado. Un análisis conceptual sobre los jugos de zar, Madrid: IPOLGOB-UC3M, 2005, p. 29. 
Administrativos y Fiscales de los Juegos de Suerte, Envite o Azar y Apuestas y una Sentencia del Tribunal Supremo (Sala de lo Civil) de 23 de febrero de 1988, que ya admite una interpretación favorable al pago, con carácter claramente contractual y de cumplimiento exigido. Ello gracias a que en el Derecho Público ya se admitió, bien que regulado, dicha exigencia de pago de la ganancia obtenida en los juegos y apuestas ${ }^{5}$.

En seguida, la Constitución Española de 1978, el artículo 148. 18, atribuye a las Comunidades Autónomas "la adecuada utilización del ocio", al mismo tiempo que la legislación económica y financiera fundamental del Reino de España, sigue siendo estatal. Los distintos tipos de juego, su naturaleza pública o privada, la demanda y oferta, la seguridad jurídica, fiabilidad, ludopatías, organización administrativa del juego, juego "en línea" (en la Resolución del Parlamento Europeo de 10 de marzo de 2009 sobre la integridad de los juegos de azar en línea) o juego virtual en Internet, blanqueo de capitales, protección a la infancia y menores de edad, régimen fiscal, disciplina sancionatoria, etc.

La Ley 13, de 27 de mayo de 2011, tras la regulación del juego supuso un cambio notable en la consideración del juego, como un instituto en Derecho Público y regulado por el Derecho Administrativo. Y todo ello, teniendo presente las normas europeas y la jurisprudencia del Tribunal de Justicia de la Unión Europea en múltiples aspectos.

\section{Aspectos de la Ley 13/2011, de 27 de Mayo, de Regulación del Juego en España y algunas sugerencias para debate en Brasil}

Importa destacar que esencialmente se trata de una Ley típicamente

${ }^{5}$ LAFAILLE.SIMONIS. Op. Cit., 2005, p. 34. 
administrativa, esto es, que lo que interesa a esta legislación es, con carácter fundamental, disponer de una serie de instrumentos de intervención pública que se atribuyen a las Administraciones Públicas.

El núcleo fundamental de la Ley es pues la regulación. Y se parte de un conjunto de prohibiciones, definiciones, y potestades de control sobre la actividad del juego. Se somete a títulos habilitantes - esto es, los títulos administrativos que permiten la realización de la actividad lúdica, y que esencialmente son licencias y autorizaciones - y a un importante régimen sancionador (aspecto típico de toda actividad intervenida públicamente).

Típicamente, el juego a que se refiere esta Ley es aquél en que se crucen cantidades de dinero, no el juego que consista en puro pasatiempo o deporte :( Se entiende por juego toda actividad en la que se arriesguen cantidades de dinero u objetos económicamente evaluables en cualquier forma sobre resultados futuros e inciertos, dependientes en alguna medida del azar, y que permitan su transferencia entre los participantes, con independencia de que predomine en ellos el grado de destreza de los jugadores o sean exclusiva o fundamentalmente de suerte, envite o azar. Los premios podrán ser en metálico o especie dependiendo de la modalidad de juego).

El objeto de la Ley es claro: la regulación de la actividad de juego, en sus distintas modalidades, que se desarrolle con ámbito estatal con el fin de garantizar la protección del orden público, luchar contra el fraude, prevenir las conductas adictivas, proteger los derechos de los menores y salvaguardar los derechos de los participantes en los juegos.

Hay que tener en cuenta, además, lo establecido en los Estatutos de Autonomía (equivalente, pari passu a las Constituciones de los Estados federados). 
$\mathrm{Y}$ hay que tener en cuenta, tema importante, que cualquier modalidad de juego no regulada se considerará prohibida (mala prohibida, es decir, son actos ilícitos porque lo dispone así la ley). Por tanto, hay una reserva de actividad, lo cual, supone que no se puede realizar juego alguno en que se cruce dinero. Hay una prohibición con reserva de dispensa, ya que quod non est permissum prohibitum intelligunt.

Ello llevó inicialmente a que fuera el Ministerio del Interior el encargado de otorgar las licencias y autorizaciones para el desenvolvimiento de la actividad. Esto es, se consideraba una actividad de policía (dentro del tríptico tradicional de actividades administrativas: policía, fomento y servicio público).

Sin embargo, más modernamente, se ha trasladado el eje de la intervención administrativa, desde la intervención basada en orden público (en sentido amplio) a la intervención fundada en recaudación fiscal. Está primando desde luego, hoy en día, la Hacienda Pública sobre la propia del Ministerio de Interior. Y, creemos, que se puede considerar que el paso futuro estará ligado a su vez, a fomento, esto es, a la actividad de promoción exterior, basada en el turismo. De ahí que indique la Ley (art. 5.1) "El Ministerio de Economía y Hacienda establecerá, por Orden Ministerial, la reglamentación básica para el desarrollo de cada juego o, en el caso de juegos esporádicos, las bases generales para la aprobación de su práctica o desarrollo".

En todo caso, existen una serie de prohibiciones objetivas (in genere la dignidad de las personas) y objetivas, basadas en circunstancias concretas: (in genere que exista un conflicto de interés- tales como árbitros, miembros del equipo jugador, o de la Comisión Nacional del Juego, y, caso curioso de auto prohibición, los de las propias personas que hayan solicitado que se les impida a ellas mismas jugar). 
La exigencia de tales "títulos habilitantes" (licencias y autorizaciones) llega al punto de extenderse a la publicidad y patrocinio de todo juego. Es decir, el título que habilita mediante la oportuna decisión administrativa a la realización de la actividad en que el juego consiste, se expande, extendiéndose a todos los aspectos ancilares y vinculados a la propia actividad de juego. Los títulos administrativos tienen pues una "fuerza expansiva" muy notable en todo lo que hace a los juegos de azar.

Tema importante y que afecta al derecho de la competencia, es el referido a la limitación del número de licencias.

Art. 10.1 Las bases que rijan la convocatoria no limitarán el número de licencias que pudieran ser otorgadas, salvo que a propuesta de la Comisión Nacional del Juego y sobre la base del procedimiento instruido a tal efecto en el que se dará audiencia a los posibles interesados, se considere necesario dimensionar la oferta del juego objeto de la convocatoria y limitar el número de operadores. La limitación del número de operadores se fundará exclusivamente en razones de protección del interés público, de protección de menores y de prevención de fenómenos de adicción al juego.

En nuestra opinión, debería en estos casos de limitación, informar, aunque con carácter no vinculante, la correspondiente Autoridad de Competencia (en Brasil, el CADE). Es clave que exista concurrencia entre operadores, pero, teniendo en cuenta todos los bienes públicos en juego (control policial, fiscalidad, atracción turística...) parece aceptable que exista esta limitación. Lo cual lleva, sin solución de continuidad, a que tales licencias se otorguen por concurso - subasta, y siempre con carácter temporal, para garantizar el mejor fruto para los intereses generales y la fluidez en los operadores económicos. Normalmente las licencias se otorgan por 10 años.

Además, naturalmente, de los requisitos comunes de este tipo de licencias y autorizaciones, tal como dice la Ley en este mismo precepto, 
que permiten que en las bases de la convocatoria se podrán incluir como criterios que habrán de ser tenidos en cuenta en el otorgamiento, la experiencia de los concurrentes licitadores, su solvencia y los medios con los que cuenten para la explotación de la licencia.

Entre los requisitos de las licencias, y muy ligado a la lucha contra la corrupción, figura el que en todo caso se tendrá presente la prevención del blanqueo de capitales (y de la financiación del terrorismo, que es un tema hoy fundamentalmente europeo, pero que en Brasil debería estar ligado al crimen organizado).

Evidentemente si se incumplen las condiciones de las licencias y autorizaciones, cae por su base el título habilitante y debe resultar caducado, debiendo cesar en la actividad.

La organización administrativa tiene dos ejes principales. De un lado, el propio Ministerio de Economía y Hacienda. Y, en segundo lugar, la Comisión Nacional del Juego (luego derogada y extinta, y cuyas atribuciones pasaron directamente a la Administración General del Estado, a través de una Dirección General) cuyo modelo, no obstante, los cambios legislativos, consideramos más útil todavía para Brasil que el modelo centralizado, dado el carácter federal de la Constitución brasileña.

De ahí que continuemos hablando de la Comisión Nacional del Juego, donde estarían representados todos los Estados brasileños.

Hoy, la regulación principal y básica corresponde al Ministerio de Economía y Hacienda. La Comisión, atiende al desarrollo de esa regulación básica y a los criterios técnicos del juego, así como la presencia efectiva in situ mediante inspecciones, auditorías, etc.

Finalmente, existe como en toda regulación administrativa, un 
régimen sancionador. Corresponde a esa Comisión la imposición de las sanciones. Las infracciones administrativas en esta materia se clasifican en muy graves, graves y leves.

Se trata de reprimir las conductas que atenten a la ordenación del juego, a las exigencias propias de un juego de azar. Conviene, descriptivamente, recordarlas. Son infracciones muy graves:

a) La organización, celebración o explotación de las actividades incluidas en el ámbito de aplicación de esta Ley careciendo del título habilitante correspondiente.

b) Realizar, promocionar, permitir o consentir, expresa o tácitamente, la organización, celebración o explotación de las actividades objeto de esta Ley en medios o soportes o por canales de distribución no autorizados y, en particular, mediante el empleo de software, sistemas de comunicación, materiales o equipos no autorizados o no homologados.

c) La cesión del título habilitante, así como su transmisión en los supuestos previstos en el artículo 9.3 de esta Ley, sin la previa autorización de la Comisión Nacional del Juego.

d) La obtención de las correspondientes autorizaciones o licencias mediante la aportación de documentos o datos falsos e inciertos.

e) El impago injustificado y reiterado de los premios que correspondieren a los participantes de los juegos. 
f) La alteración o manipulación de los sistemas técnicos previamente homologados o de cualquier otro elemento relativo a la obtención de premios en perjuicio de los participantes.

g) La realización de actividades de juego infringiendo la reserva establecida en el artículo 4 de esta Ley.

h) La comisión de dos infracciones graves en el plazo de dos años, con sanción definitiva en vía administrativa.

i) El desarrollo y la comercialización a través de Internet de actividades de juego en el ámbito de aplicación de esta Ley, que no sean realizadas en el sitio web específico bajo «.es» establecida en esta Ley.

j) El incumplimiento de la obligación de redireccionamiento referida en esta Ley.

Puede comprobarse como se trata de los ataques más severos a los títulos habilitantes. Se exponen simplemente, ya que ahora, en este trabajo, lo que se pretende es iniciar el estudio a los juegos de azar, por lo que solamente una monografía completa nos ofrecería espacio para su comentario. Asimismo, y con graduación clara, existen las infracciones graves. Obsérvese de nuevo la graduación de las infracciones. Son infracciones graves:

a) El incumplimiento de los requisitos y condiciones fijados en el título habilitante $y$, en particular, de los deberes de control para garantizar la seguridad de los juegos.

b) Permitir el acceso a la actividad de juego a las personas que lo tienen prohibido, de conformidad 
con el artículo 6 de esta Ley, siempre que la entidad explotadora de juegos conozca o deba conocer la concurrencia de tales prohibiciones.

c) La concesión de préstamos o cualquier otra modalidad de crédito a los participantes por parte de los operadores.

d) Efectuar la promoción, patrocinio y publicidad de los juegos objeto de esta Ley, o actuaciones de intermediación, cuando quienes lo realicen carezcan de título habilitante o se difundan con infracción de las condiciones y límites fijados en el mismo o infringiendo las normas vigentes en esta materia, cualquiera que sea el medio que se utilice para ello.

e) El incumplimiento de los requerimientos de información o de cese de prestación de servicios dictados por la autoridad encargada de la regulación del juego que se dirijan a los proveedores de servicios de pago, prestadores de servicios de comunicación audiovisual, prestadores de servicios de la sociedad de la información o de comunicaciones electrónicas, medios de comunicación social, agencias de publicidad y redes publicitarias.

f) La obstrucción, resistencia o excusa a la función de inspección y control así como la ocultación o destrucción de la información, documentos o soportes de la misma.

g) La negativa reiterada de los operadores $\mathrm{u}$ organizadores a facilitar la información que le sea requerida por la Comisión Nacional del Juego.

h) La negativa reiterada a atender las reclamaciones o quejas formuladas por los participantes o la Comisión Nacional del Juego. 
i) El incumplimiento de las obligaciones de comunicación de aquellas modificaciones efectuadas en la composición, sede, capital y titularidad de las acciones o participaciones de las personas jurídicas habilitadas, en el plazo de tres meses desde que se hubieran realizado.

j) El incumplimiento de los requisitos técnicos de los reglamentos o del pliego de bases relativos al software y a los sistemas de comunicación.

k) La utilización de sistemas técnicos no homologados o no autorizados.

1) La fabricación, comercialización, mantenimiento o distribución de material de juego propiedad de los operadores que desarrollen actividades de juego objeto de reserva en esta Ley sin la debida autorización.

m) El impago de los premios que correspondieren a los participantes en los juegos.

n) La comisión de dos infracciones leves en el plazo de dos años, con sanción definitiva en vía administrativa.

Finalmente, existen infracciones leves:

a) La participación en actividades de juego, contraviniendo las prohibiciones establecidas en esta Ley. 
b) Los incumplimientos de las obligaciones contenidas en esta Ley, cuando no estuvieren expresamente tipificadas como infracciones graves o muy graves.

c) No colaborar con los inspectores o agentes de la autoridad en relación con el desarrollo de las actividades de juego o lo relacionado con la comprobación del sorteo o evento en cuya virtud se obtengan los premios.

d) No informar debidamente al público de la prohibición de participar a los menores de edad y a las personas incluidas en el Registro General de Interdicciones de Acceso al Juego.

e) No informar al público sobre el contenido del título habilitante del operador de juego.

Por ultimo, cabe indicar que las sanciones son acordes con la infracción cometida

1. Las infracciones calificadas como leves serán sancionadas por la Comisión Nacional del Juego con:

a) Apercibimiento por escrito.

b) Multa de hasta cien mil euros.

2. Las infracciones calificadas como graves serán sancionadas por la Comisión Nacional del Juego con las siguientes sanciones:

a) Multa de cien mil a un millón de euros.

b) Suspensión de la actividad en España por un plazo máximo de seis meses. 
3. Las infracciones calificadas como muy graves serán sancionadas por el titular del Ministerio de Economía y Hacienda, a propuesta de la Comisión Nacional del Juego, con multa de un millón a cincuenta millones de euros.

Además de la multa, podrá imponerse la pérdida del título habilitante, la inhabilitación para la realización de las actividades previstas en el artículo 1 de esta Ley por un período máximo de cuatro años o la clausura de los medios por los que se presten servicios de la sociedad de la información que soporten las actividades de juego.

\section{La idea de los sectores o categorías del Jugos de Azar en Europa Y las Posibilidades para Brasil}

\section{A) Loterías}

A.1) Lotería Nacional. En España es un juego antiguo. El primer sorteo fue celebrado el 10 de diciembre de 1763, realizado por impulso del Monarca Carlos III, quien previamente había sido Rey de Nápoles, y utilizó la fórmula que hoy conocemos como "Lotería Primitiva", esto es, el juego consistente en acertar una combinación numérica tras rellenar un boleto a mano por el jugador.

Luego, tras la Guerra de la Independencia contra Napoleón, en 1811, adoptó la forma actual consistente en un juego de azar por el que el jugador compra un "billete", que se divide en "décimos" y tras un sorteo público, quien acierta el número, se lleva el premio; y existen segundos y terceros premios, cada uno con una recompensa numérica. 
Aunque hay sorteos periódicos, el más importante es "El Gordo", que corresponde con el Sorteo Extraordinario de Navidad, probablemente el mayor sorteo de lotería de todo el mundo. Es todo un acontecimiento nacional, cultural, insertado en la mente de las familias, de los pueblos y villas, retransmitido por televisión y aceptado como elemento importante de las fiestas de Navidad. Luego hay otros varios sorteos importantes y también semanales, unidos a los extraordinarios que pueden atender a diversas causas.

La extraordinaria popularidad de este juego se basa en un bien descrito fenómeno "psicológico - económico", denominado "envidia preventiva" (alarma individual consistente en que toque el premio a los amigos, conocidos...y además enterarse). Por eso, es frecuente la compra colectiva (en empresas, organizaciones de todo tipo) en que todos compran el mismo número... por si acaso. También se une cierta generosidad, al repartir entre amigos y familiares, con el deseo, de "felicidad preventiva", esto es, de comprobar que uno actúa como un Ángel repartiendo prosperidad a los demás. Cara y cruz de la misma moneda, ello lleva a que se juegue anualmente una cantidad cercana a los 5.000 Mills., de Euros, repartiendo en premios unos 3.300 Mills., de Euros., y ofreciendo al Estado, unos 1700 Mills., de Euros (cifra global promediada de los últimos 25 años, aproximadamente y de forma general para ofrecer un panorama al lector $)^{6}$. Su transparencia es total, siendo la clave de su subsistencia a lo largo de varios siglos.

A.2) Lotería Primitiva. Como en muchas sociedades latinas, el juego, forma festiva y recreativa, es un componente lúdico del ocio que permite al ciudadano una distracción y felicidad enorme. Lo cual se traduce en que, debidamente fomentado por los poderes públicos, no exista una sola variedad de juego, ni siquiera dentro de los mismos géneros.

\footnotetext{
${ }^{6}$ YÁÑEZ, J.A. Gómez et all. Anuario del Juego en España. Madrid: Fundación CODERE. 2016, p. 148.
} 
Y eso sucede con la Lotería, en que además de la fuerte presencia de la Lotería Nacional, cobra fuerza creciente la original "Lotería Primitiva", ya descrita ut supra. A su vez, la Lotería Primitiva, se desglosa en diferentes variantes: "La Primitiva", "E1 Joker", "Bonoloto", "E1 Gordo de la Primitiva", "Euromillones".

Las ventas anuales, globalmente consideradas, rondan aproximadamente los 4.000 Mills., de Euros. Los premios alcanzan cerca de los 2.000 Mills. de Euros. Y por tanto el beneficio para las arcas públicas, en forma de margen, otros 2.000 Mills. de Euros ${ }^{7}$.

B) Apuestas Deportivas

Aquí, el juego de azar se combina con el conocimiento del jugador, quien se supone apuesta sabiendo por su experiencia quien es el mejor deportista. Hoy son crecientes las apuestas en línea si bien las prototípicas en España han sido las futbolísticas e hípicas.

En las futbolísticas presenciales de gestión pública, la financiación de los distintos clubes de futbol vía derechos de imagen, obliga a dispersar la retransmisión televisiva, fragmentándola en horarios incompatibles con la atención continuada al resultado de los partidos. La consecuencia es una cierta disminución del volumen de apuestas y la creación de un mercado "nicho" para aficionados estrictos al balompié. Así en el año 2015, generó un volumen de ventas de 268,5 Mills. de Euros. En premios repartió 157,5 Mills. de Euros. Y el impuesto para el Estado fue de 59 Mills. de Euros. Otra fórmula llamada Gol (acertar número de goles) genera apenas 10 Mills. de Euros ${ }^{8}$.

${ }^{7}$ YÁÑEZ, J.A. Gómez et all. Op. Cit. , 2016, p. 149.

${ }^{8}$ YÁÑEZ, J.A. Gómez et all. Idem, 2016, p. 150. 
Y en cuanto a las apuestas hípicas, debido a la mala gestión de los hipódromos, apenas genera un volumen de 5 Mills. de Euros ${ }^{9}$.

En ambos casos, la regulación es estatal, se gestionan por la SELAE, y continúan una larga tradición, en que tampoco hubo escándalos ni corrupciones, lo que permitió que estos juegos, que nacieron en una gallera de Santander en 1929, hayan podido continuar (Bar gallera, "La calle altera"). Pero están destinados a reducirse paulatinamente, aunque siempre tendrán su público.

Al mismo tiempo, existen apuestas deportivas de gestión privada, que en salones de juegos, bares, (además de Internet), están autorizadas en determinadas Regiones. Y su volumen ya sí es alto, alcanzando en 2015 los 1.215 Mills., de Euros ${ }^{10}$.

\section{C) Organización Nacional de Ciegos Españoles (ONCE)}

La ilusión del juego organizado por esta Corporación de Derecho Público supervisada por la Administración Pública se combina con su acción social. Es pues privada, como toda corporación, aunque tenga una fuerte intervención pública, similar a la de un Colegio profesional (de Abogados por ejemplo). Pero, además, se extrema la supervisión administrativa con el fin de garantizar que su amplio patrimonio acumulado durante décadas, continúe intacto al servicio de sus finalidades sociales, que sabemos consiste en el cuidado de los ciegos y, después, de otros colectivos necesitados por su discapacidad.

Actualmente sufre la competencia de otras variedades de lotería, lo que lleva a un cierto estancamiento en sus ventas, pese a su popularidad. El carácter solidario ha sido un incentivo para su mantenimiento, pero la existencia de esa concurrencia, hay que insistir, lleva a una cierta hibernación de su penetración en los mercados de juegos de azar. En el

\footnotetext{
${ }^{9}$ YÁÑEZ, J.A. Gómez et all. Idem, 2016, p. 150-151.

${ }^{10}$ YÁÑEZ, J.A. Gómez et all. Idem, 2016, p. 152.
} 
último año registrado (2015) su volumen de negocios fue de 1806 Mills., de Euros ${ }^{11}$.

\section{D) Bingos}

En el último año registrado, 2015, en España había 308 salas de Bingo abiertas, algunas más en fase de cierre ${ }^{12}$. Normalmente de naturaleza estrictamente privada, pero como todo el juego, sujeto a supervisión para evitar cualquier clase de estafa. Las localidades alcanzan 110.000 con una media de 335 por cada Sala de Bingo ${ }^{13}$. Las normas son de carácter regional (estatal en Brasil), y son muy diferentes, ya que hay Regiones que establecen limitaciones al número de salas y otras que fijan distancia entre las salas y finalmente, otras que permiten la completa libertad de establecimiento. Unen en muchas ocasiones máquinas de juego que complementan el clásico "cartón” de bingo. El número de visitas alcanza la estimación de 37, 5 millones de jugadores ${ }^{14}$.

El Bingo va conociendo la modalidad de "Bingo electrónico" que sin duda va creciendo y la totalidad de facturación alcanza la cantidad de 1846,54 Mills. de Euros ${ }^{15}$.

E) Casinos

Sin duda alguna, ligados al sector turístico - del que también deben formar parte- al constituir un centro de atracción permanente, estable, perfectamente identificado y en el que el viajero y el turista conoce de antemano la existencia de un lugar de esparcimiento, de carácter

\footnotetext{
${ }^{11}$ YÁÑEZ, J.A. Gómez et all. Idem, 2016, p. 154.

${ }^{12}$ YÁÑEZ, J.A. Gómez et all. Idem, 2016, p. 156.

${ }^{13}$ YÁÑ̃EZ, J.A. Gómez et all. Idem, 2016, p. 157.

${ }^{14}$ YÁÑEZZ, J.A. Gómez et all. Idem, 2016, p. 159.

${ }^{15}$ YÁÑEZ, J.A. Gómez et all. Idem, 2016, p. 163. 
recreativo en el que puede resultarle grata estancia por algún tiempo para su diversión lúdica. Y ello multiplicado por los cruceros, que pueden desembocar en los puertos brasileños para incorporar a turistas y viajeros a sedes de diversión formalizadas en las que exactamente el Casino sea el centro de gravedad permanente de su recreo. Se multiplica así la oferta turística, sin duda. Así ocurre en lugares bien conocidos mundialmente, como Estoril en Portugal o Mónaco.

Por consiguiente, es clave que todas las políticas y sus regulaciones, sobre los Casinos, estén unidas a una estrategia turística, sin la cual, el público nacional por sí solo, no dará suficiente para constituir un recurso generador de toda una escala de negocio. Hay que pensar en el turista - interior y extranjero- e incorporar el Casino dentro de una política y derecho del turismo.

En España, hoy, la legislación del juego tiene gran parte de regional, sin perjuicio de algunas reglas básicas nacionales. En total, existen unos 50 casinos en España (incluyendo salones de juego con permiso de jugar ruleta y póker) ${ }^{16}$.

Ello comporta la ventaja de una cierta "competencia entre legislaciones", configurando distintos mercados de juego en casinos.

Pero no se puede ocultar que tal fragmentación implica también una dispersión que puede ofuscar al jugador, de forma que haga más difícil al turista y al viajero, tener una idea clara de la oferta turística global; lo cual supone una desventaja en determinados ofrecimientos de atracción turística. Porque quien ocupa su tiempo en el ocio, normalmente, desea simplemente la diversión esporádica. Y ésta es la gran masa de turistas y viajeros. Ciertamente hay jugadores casi profesionales y eventualmente algunos ludópatas. Pero, estadísticamente, tales nichos de mercado no son relevantes, y cualquier consultor estratégico apostaría - permítase el juego de palabras - por lograr una armonización legal y administrativa que

${ }^{16}$ YÁÑEZ, J.A. Gómez et all. Idem, 2016, p. 174. 
permitiera unas mayores facilidades de identificación del juego de azar en Casinos.

El citado "Anuario" indica que es relevante la contribución a la conservación del patrimonio histórico artístico, ya que existen Casinos que se han instalado en edificios emblemáticos, en antiguas y tradicionales salas de cine - así preservadas de la demolición - lo que supone una vertiente cultural no desdeñable, a la que puede sumarse, en su caso, la edificación de nuevos Casinos con grandes arquitectos que innoven la ciudad, que aporten genuinos centros de atracción que en sí mismo constituyan otro "faro" turístico ${ }^{17}$.

El producto clásico de los casinos, la ruleta - en sus distintas variantes- tiene unido ya, indisolublemente, las máquinas, las cartas - con una especial especificidad respecto del juego del póker - y paulatinamente aparecen añadidos diferentes (restauración, eventualmente salones para otros recreos). Y, como bien señala el citado Anuario las clases sociales que juegan, no son necesariamente de status social alto, sino incluye también el medio.

El póker, con reglas de disciplina bien establecidas universalmente, con sus diferentes variedades, exige un conocimiento y habilidad específicos. Bellamente lo expresa la citada publicación: "Hay otro segmento muy claro, el de los jugadores de póker, en el que el rasgo distintivo es el conocimiento de las reglas del juego, y una concepción del juego como competición, como demostración de que se juega mejor que los rivales. Dicho de otra manera, los juegos de casino son la esencia de los juegos de pasión racionalizada, de habilidad y entretenimiento, pero también para socializar con personas con bastantes afinidades, además, es la ocasión para ganar dinero, pero esto no es lo que mueve principalmente a los clientes".

${ }^{17}$ YÁÑNZ, J.A. Gómez et all. Idem, 2016, p. 183-186. 
Clave en los Casinos sigue siendo la absoluta fiabilidad de los juegos, siendo capital que toda la legislación permita garantizar por distintas vías, que la famosa escena de Casablanca, "He dicho el 22", no se repita. Literalmente, sin hipérbole, un Casino como el Rick`s no puede darse: el efecto "contagio reputacional" hundiría la totalidad del sector y Brasil quedaría señalado como un país al que no se puede ir a jugar, con la pérdida considerable también en el sector turístico.

En consecuencia, la legislación sobre Casinos, ha de ser estricta, con una fuerte presencia interventora e inspectora de la Administración, que a su vez, tiene que ser examinada por "asuntos internos".

Los ingresos de los Casinos, se sitúa en torno al $20 \%^{18}$. Los nuevos jugadores, tras la crisis, dejan menos propinas, reduciéndose así un ingreso extraordinario pero típico.

En crisis todavía, las cantidades entre fichas y máquinas en los casinos españoles, alcanzó la cantidad de 1636 Mills. de Euros ${ }^{19}$. El margen de los casinos fue de 307,5 Mills. de Euros. Y los impuestos llegaron a la cantidad de 61,8 Mills. de $\operatorname{Euros}^{20}$.

$\mathrm{Y}$ un dato importante, que hay que relacionar es el número de visitantes a los casinos, que pagan entradas, aunque no jueguen, que cenan o almuerzan o beben en sus barras y restaurantes, y que se desplazan con todo el movimiento indirecto que supone ese punto de atracción. Alcanzó en 2015 los 5.171 .0000 visitantes $^{21}$, cifra no desdeñable y que puede multiplicarse exponencialmente en Brasil. De nuevo hay que insistir: el impacto turístico sería excepcional, con todo lo que ello conlleva.

Indudablemente, Internet también revoluciona el juego en los casinos. El juego en línea, transforma también al clásico casino presencial y entre los miembros de la "generación digital", provoca una creciente

\footnotetext{
18 YÁÑEZ, J.A. Gómez et all. Idem, 2016, p. 187.

${ }^{19}$ YÁÑEZ, J.A. Gómez et all. Idem, 2016, p. 188.

${ }^{20}$ YÁÑEZ, J.A. Gómez et all. Idem, 2016, p. 189.

${ }^{21}$ YÁÑEZ, J.A. Gómez et all. Idem, 2016, p. 190.
} 
afición. Por ello, dado que este tipo de casino será previsiblemente creciente, la insistencia en los casinos clásicos unidos a una oferta turística que obligue a la presencia, esto es, espectáculos, restauración, hotel, dentro de un circuito completo de oferta viajera, es esencial. Es la manera de rentabilizar esas inversiones, de que produzcan a su vez, impacto sobre el resto de los sectores ligados al turismo, de aumentar el atractivo de la visita al país.

\section{Una Perspectiva Binaria: España y Brasil}

Un elemento capital aparece como esencial: transparencia y datos claros. Sin una decidida voluntad política de disponer de números, estadísticas y hechos, en fin, sobre la realidad del juego en todas sus modalidades, la Hacienda Pública carecerá de medios para exigir impuestos, que es la fuente de la riqueza pública en este sector. Asimismo, sin transparencia, pueden surgir de inmediato corrupciones y toda su secuela delictiva (mafias) que ocasionarán graves daños sociales y personales.

La "tasa social de beneficios" debe ser muy alta para que el juego sea productivo en una sociedad. Es decir, no nos encontramos ante un juego de "suma cero" si introducimos una legislación sobre juegos de azar; al contrario, será de suma positiva o negativa. Si existe una regulación apropiada que logre que la tasa social de beneficios, en forma de impuestos, empleo, turismo... aumente, será un elemento claramente beneficioso para la sociedad brasileña. $\mathrm{Si}$, por el contrario, nos encontramos ante introducción del juego en una forma poco transparente, sin publicidad jurídica, sin control administrativo, sin concurrencia en la adjudicación, sin seguimiento en su desempeño, la tasa social de beneficios será negativa, existirán pérdidas netas en forma de delincuencia, corrupción, desprestigio estatal, etc. 
De ahí, la enorme importancia de contar con una legislación apropiada y un régimen jurídico preventivo y sancionador, basado en criterios independientes, en los que la imparcialidad, objetividad, neutralidad del juzgador, que ha de ser totalmente despolitizado, constituya la base de un critérium claro, que conforme una atractiva y amigable legislación para toda clase de inversores, incluidos los extranjeros (por lo que adelantamos ya, es imprescindible acudir al arbitraje para solventar con rapidez y especialidad los conflictos que se planteen, tema que nos ocupará al final de este trabajo) .

Asimismo, en Brasil, como en España, al ser Estados descentralizados, se corre el riesgo de la dispersión normativa, de forma que cada Estado tenga su propia legislación, administración y al final, percepción muy distinta sobre lo que los juegos de azar significan. Pero Brasil, como oferta unitaria turística (aspecto muy unido al juego en el aspecto exterior) exige que se disponga de una homogeneización que permita tanto al jugador extranjero como al nacional, tener una idea clara y previa, de cómo funcionará el juego.

Cada tipo de juego, a su vez, tiene su propia "intrahistoria", siendo muy diferentes de unos sitios a otros y desde luego resultando esencial la cultura popular y general de cada país. Y es que son múltiples, variados y evolutivos los diferentes tipos de juego. Así, toda clase de Loterías, públicas y privadas, clásicas y primitivas - rifas y tómbolas, apuestas de muy diverso tipo, juegos virtuales en Internet, Casinos, Bingos, Quinielas de Fútbol, etc., etc.

Sectores que dan empleo directo a 80-761 persona e indirectos a 160.000 personas, lo que no es desdeñable. Y los impuestos sobre el juego, en total, agregadamente, alcanzaron la cifra de 1.638 Mills. $€$.

Conviene destacar, quizás como peculiaridad española, que en España, además de juegos organizados por Administraciones Públicas (como Loterías y Apuestas del Estado, de la Sociedad Estatal Loterías y 
Apuestas del Estado, S.A. (SELAE), y las loterías privadas (muy presentes "on line") existe tradicionalmente una organización social de loterías muy típica e históricamente muy fuerte, la ONCE, Organización Nacional de Ciegos Españoles, que ha sido un prototípico avance, desde el 13 de diciembre de 1938, y cuyos famosos boletos han impulsado una inmensa obra social de recuperación de los ciegos y luego, por extensión, de otros minusválidos. Sería de gran interés, explorar asimismo en Brasil una organización semejante, con la finalidad que se considere oportuna, mimetizando el papel que tienen las "charities" en el mundo anglosajón, pero con una regulación similar a la española de juegos de azar.

De otra parte, en el ámbito privado, tanto en el plano presencial como en el plano virtual, es clave recordar que "el Juego no es un juego para no iniciados", porque las empresas han de contar con una fuerte y robusta estructura organizativa y tecnológica. De ahí que, sin constituir un oligopolio, el número de actores en el sector empresarial no pueda ser muy amplio, más bien es pequeño en lo que hace a los grandes juegos de masa, con destinatario universal. Simultáneamente, en los pequeños juegos (rifas, tómbolas...) existen numerosos y cambiantes pequeños operadores, que ofrecen sus productos en villas, pueblos, pequeñas ciudades... O que simplemente, centren su actividad en determinados juegos, como algunos salones de bingo, máquinas tragaperras, máquinas de juego, etc.

Sin embargo, en el ámbito de los grandes juegos de masa, destinados a millones de ciudadanos, y ahora, a través de Internet, con carácter universal, la tendencia al oligopolio es fuerte. Ello es debido a la ingente tecnología que se necesita para atender a tal demanda, garantizar la legalidad y limpieza de los juegos y lograr una aceptación doble: social y estatal. Social, ya que quienes juegan han de confiar en el operador siempre, de forma que el prestigio ganado tras esfuerzo continuado puede verse destruido por un solo caso de alteración o trampa, y estatal, ya que se trata de que el Estado, a través de su Administración Pública, disponga de todos los instrumentos necesarios para garantizar los derechos de los 
jugadores y al mismo tiempo, obtener la fiscalidad correspondiente, fijada previamente en normas claras, precisas y fácilmente aplicables.

La existencia de tales oligopolios, implica automáticamente, la necesaria aplicación del derecho de la competencia. Es decir, que haya unas barreras de entradas perfectamente determinadas y legalmente superables, y que se eviten posiciones de dominio, incluidas las posiciones dominantes colectivas, típicas de los oligopolios.

Es importante destacar que el Estado, puede regular, por razones de garantía de juego limpio - en definitiva, una aplicación del concepto de "policía de espectáculos públicos" (que son simplemente espectáculos dedicados al público y realizados en lugar público, aunque sean sujetos privados los que los realicen), las propias "reglas del juego", el otorgamiento de autorizaciones o concesiones - con inclusión de distancias mínimas entre establecimientos de juego, licencias de apertura, horarios, policía "strictu sensu", facilidades y esparcimientos asociados al juego, etc., en definitiva, la totalidad prácticamente de los elementos que configuran el propio mercado del juego. De nuevo, la razón última es la doble argumentación de la fiscalidad y del juego limpio, esto es, la protección del Estado en la obtención de recursos y la de los ciudadanos en la de los premios.

Lo cual lleva, sin solución de continuidad, a la exigencia ineludible de un órgano independiente, experto, permanente, vigilante y vigilado al mismo tiempo, en el que la transparencia y publicidad de sus actuaciones, incluidas sus resoluciones, sea clave para asegurar la limpieza del mercado de juego.

A destacar en tal organización administrativa, tanto la experiencia, como su solvencia técnica, y desde luego, admitiendo que solamente un órgano permanente, puede abordar la complejidad organizativa en que se desenvuelven estas empresas y los grupos empresariales que participan en este mercado (complejidad que no es conocida ni valorada por el público 
en general, pero que basta con examinar cualquier juego de carácter universal, dedicado a todos los públicos, para comprender de inmediato lo complicado y complejo que resulta ser esta actividad).

En otras palabras, los mercados de juego, según los diferentes niveles, son, al modo de las viejas "Ferias y Mercados" medievales, protegidos e intervenidos por el Poder público, para garantizar, de nuevo al igual que en el Medioevo, la fiabilidad del propio mercado. Y ello, incluye también el control y supervisión de grupos empresariales internacionales en cuanto operen en el país de destino, sea Brasil, sea España, sea el que fuere. Se advierte en este sentido del inmenso poder de las organizaciones multinacionales, por lo que el organismo correspondiente deberá tener una visión internacional mediante el Acuerdo o Tratados con organismos semejantes con los que sería recomendable que actuara "en red", continuamente.

Por ello, es imprescindible que exista una Memoria Anual del organismo Federal correspondiente, que incluya todo el histórico del juego y también propuestas de mejora.

Histórico, que ha de recoger toda la diversa estructura empresarial, por distintos tipos de juego, así como la organización administrativa cuando el operador sea público.

En el caso de operadores privados, asimismo ha de contener esa Memoria, la referencia a las patronales del juego, ya que ahí, precisamente ahí, en las organizaciones patronales, puede surgir la posibilidad de acuerdos contra el derecho de la competencia. Es típico que sean las organizaciones las que, al tener unidos colectivamente a los diferentes operadores, sean quienes den ocasión a la existencia de cárteles de todo tipo. En consecuencia, esa Autoridad u Órgano que se cree en Brasil, ha de tener una estrecha relación con el CADE, y en la legislación correspondiente tiene que establecerse esa ligazón, ese enlace entre la Autoridad de Competencia y la Autoridad de Juego. Ahora bien, dicho lo 
anterior, también habría que destacar que para la propia Administración tiene interés que exista una "Federación" de las distintas Asociaciones patronales, evitando la dispersión que supone para el Estado Brasileño que existan múltiples patronales pequeñas, fragmentando la interlocución. Un interlocutor general, aunque en su interior, en su seno, tenga varias voces, puede ser útil para los grandes temas (fiscalidad, por ejemplo, o policía de espectáculos, protección de menores...etc.). La debilidad patronal puede traducirse en ineficiencia administrativa, ya que toda decisión se retrasaría, sería enormemente lenta, pesada, complicada y con intereses muy distintos. En definitiva, que junto con las Asociaciones patronales locales o por sectores de juego, puede ser muy recomendable que se impulse una Federación o al menos una Confederación Nacional para determinados grandes temas, para tener una completa "visión de la jugada", una visión general también.

\section{Breve Reflexión Final}

Los juegos de azar, han pasado por varias fases a lo largo de su evolución histórica. Siempre ligados a actividades lúdicas, desde la Antigüedad, en el mundo occidental tuvieron una fase crítica ligada al puritanismo, cuando se cruzaba dinero en las diferentes combinaciones que la suerte o fortuna, permitía.

Son múltiples y de naturaleza diversa, desde los que se basan en la pura alea hasta los que combinan la misma con la destreza y habilidad; desde los meramente deportivos, basados en el esfuerzo y reglas del juego del deporte, hasta los que suponen un simple riesgo basado en el puro albur, siendo aquí la mera contingencia la decididora del resultado favorable o desfavorable. 
Jurídicamente han pasado del ámbito estrictamente civil, al propiamente administrativo, cuando la permisión del juego alcanzó a todas las clases sociales y a todos los diferentes tipos de combinaciones.

El Estado, inicialmente, reguló el juego por vía civil y como actividad estrictamente de la esfera privada, dándole la consideración de obligación natural, esto es, la que no supone un deber estricto de cumplimiento, pero que sí produce efectos jurídicos, fundamentalmente, el derecho de retención por quien resulta acreedor en el resultado del juego, supuesto que hubiera pagado quien resulte deudor.

Luego, cuando de forma masiva, el juego pasa a ser considerado un elemento más de la actividad social, y por tanto la cotidianeidad es lo común, el Estado interviene. Primero como protector de los intereses del común de los jugadores, a través de la técnica de la policía administrativa. Luego, suma a dicha consideración, la puramente fiscal, esto es, se aproxima desde la visión de la Hacienda Pública.

Y hoy en día, está en juego, valga la redundancia, que los juegos de azar sean signo de atracción turística, por lo que la oferta turística será un elemento fundamental en su consideración administrativa.

Las tres técnicas tradicionales administrativas, de fomento (turismo), servicio público (juegos del Estado) y policía (títulos habilitantes en juegos privados) se dan cita en este mundo del juego.

Jugar bien estos tres títulos, como si de tres cartas de naipes fuera, será lo que permita al Estado brasileño, obtener el gran premio en que consiste el juego: un saneado ingreso fiscal, un polo de atracción turística y una transparencia atractiva para los inversores. 


\section{Referencias}

ESPAÑA, Leyes. Código Civil Español, de 1889 y Ley 13, de 27 de mayo de 2011.

LAFAILLE, Jean-Marc. SIMONIS, Guy. El juego diseccionado. Un análisis conceptual sobre los jugos de zar, Madrid: IPOLGOB-UC3M, 2005.

OLMEDA, Alberto Palomar. Sobre la nueva regulación del juego. In: Revista Aranzadi Doctrinal, ISSN 1889-4380, Nº 7 (noviembre 2011), 2011, págs. 49-62.

- Juego, apuestas y deporte: algunas consideraciones para una reflexión general. In: Estudios jurídicos, ISSN-e 1888-7740, N 7, 2007.

La regulación del mercado de juego en España: justificación, modelo previsto y perspectivas de futuro. In: En torno al juego de azar: actividad, regulación y actores / coord. por Alberto Palomar Olmeda, Rafael Baena Zapatero, 2013, ISBN 978-84-9903-749-3, págs. 31-122

. Los títulos habilitantes para el ejercicio de la actividad de juego. In: El nuevo régimen jurídico de los juegos de azar: comentario a la Ley Estatal 13/2011, de regulación del juego / coord. por Olga Herráiz Serrano, 2012, ISBN 978-84-8126-669-6, págs. 389-434

. La delimitación de la actividad de juego y las actividades asimiladas. Régimen administrativo y distribución competencial. In: El juego on line. Coord. por Alberto Palomar Olmeda, 2011, ISBN 978-848355-919-2, págs. 265-366

La ordenación legal del juego en España: El papel de las administraciones públicas en materia de juego: Régimen del juego en España / coord. por Alberto Palomar Olmeda, 2006, ISBN 84-9767-6483, págs. 77-130

. (Coord.), Rafael Baena Zapatero (Coord.). En torno al juego de azar actividad, regulación y actores. Madrid: Editorial Aranzadi, 2013. 
. (Coord.) Régimen del juego en España. Madrid: Editorial Aranzadi, 2006.

PARLAMENTO EUROPEU, Resolución del Parlamento Europeo, de 10 de marzo de 2009 sobre la integridad de los juegos de azar en línea. YÁÑEZ, J.A. Gómez et all. Anuario del Juego en España. Madrid: Fundación CODERE. 2016. 